Wright State University

CORE Scholar

$8-2000$

\title{
Regional Variation in Recruitment of Hemlock Seedlings and Saplings in the Upper Great Lakes, USA
}

\author{
Thomas P. Rooney \\ Wright State University - Main Campus, thomas.rooney@wright.edu \\ Ronald J. McCormick \\ Stephen L. Solheim \\ Donald M. Waller
}

Follow this and additional works at: https://corescholar.libraries. wright.edu/biology

Part of the Biology Commons, Medical Sciences Commons, and the Systems Biology Commons

\section{Repository Citation}

Rooney, T. P., McCormick, R. J., Solheim, S. L., \& Waller, D. M. (2000). Regional Variation in Recruitment of Hemlock Seedlings and Saplings in the Upper Great Lakes, USA. Ecological Applications, 10 (4), 1119-1132.

https://corescholar.libraries.wright.edu/biology/74

This Article is brought to you for free and open access by the Biological Sciences at CORE Scholar. It has been accepted for inclusion in Biological Sciences Faculty Publications by an authorized administrator of CORE Scholar. For more information, please contact library-corescholar@wright.edu. 


\title{
REGIONAL VARIATION IN RECRUITMENT OF HEMLOCK SEEDLINGS AND SAPLINGS IN THE UPPER GREAT LAKES, USA
}

\author{
Thomas P. Rooney, ${ }^{1,4}$ Ronald J. McCormick, ${ }^{2}$ Stephen L. Solheim, ${ }^{3}$ And Donald M. WalleR ${ }^{1}$ \\ ${ }^{1}$ Department of Botany, 430 Lincoln Drive, University of Wisconsin, Madison, Wisconsin 53706 USA \\ ${ }^{2}$ Institute For Environmental Studies, University of Wisconsin, Madison, Wisconsin 53706 USA \\ ${ }^{3}$ Department of Biology, University of Wisconsin, Whitewater, Wisconsin 53190 USA
}

\begin{abstract}
Mature eastern hemlock-northern hardwood forest cover decreased drastically in the upper Midwest following European settlement and has yet to rebound substantially. Previous studies show that stands retaining substantial hemlock canopy coverage have low hemlock seedling and sapling densities. Results from various geographically restricted studies suggest several possible mechanisms that could cause low seedling or sapling density. We examined the relative importance of these proposed mechanisms in the Southern Superior Uplands Section of the Laurentian Forest Province. We surveyed 294$\mathrm{m}^{2}$ plots in 100 hemlock stands in northern Wisconsin and western upper Michigan to assess how these proposed mechanisms affect the number of hemlock seedlings and saplings in four sequential size classes. Seedling and sapling abundance increases with greater light availability and differs significantly among geographically distinct ecological units (ecological subsections). In contrast, the abundance of medium and large saplings (30-99 and $100-300 \mathrm{~cm}$ tall) appears unrelated to light and geographic factors but declines as deer browsing increases, diminishing recruitment of larger saplings. The abundance of seedlings and saplings in each size class also depends strongly on the number of seedlings or saplings in the next smaller size class at the same site, reflecting demographic inertia. Path analysis integrates and separates these effects, explaining $24 \%$ of the regional variation in seedling abundance, $63 \%$ of small sapling abundance, and $\sim 80 \%$ of medium and large sapling abundance. Light and ecological subsection directly affect the number of seedlings and small saplings, whereas deer browsing directly affects the number of medium saplings. Demographic inertia remains important for all larger size classes. These results imply that restoring hemlock populations requires both appropriate microsites for seedling establishment and sanctuary from excessive browse for successful recruitment.
\end{abstract}

Key words: deer browsing; ecosystem management; geographic subsections; limiting factors; path analysis; regional survey; sapling recruitment; seedling establishment; tree demography; Tsuga canadensis.

\section{INTRODUCTION}

A primary goal of ecosystem management is to maintain native biological diversity in managed landscapes (Perry 1994, Kohm and Franklin 1997). Managing for biological diversity requires more than simply ensuring the population viability of the species that occur within a management boundary. Landscape connectivity also needs to be maintained (Noss and Cooperrider 1994, Wiens 1997). In some forest landscapes not altered by human disturbance, a primary forest cover type provides landscape connectivity (Pastor and Broschart 1990). Appropriate management of such forest landscapes might involve commodity use integrated within a matrix of native primary vegetation types and seral stages (Mladenoff et al. 1994, Noss and Cooperrider 1994). However, most forest landscapes have been altered by past human activity. In cases where the primary forest cover type has been reduced in size and

Manuscript received 30 November 1998; revised 17 May 1999; accepted 9 August 1999.

${ }^{4}$ E-mail: tprooney@students.wisc.edu extent by past management practices, ecological restoration of that forest landscape needs to play an integral role in ecosystem management.

In the hemlock-northern hardwood forests of the Southern Superior Uplands Section (Keys et al. 1995; Fig. 1), stands dominated by eastern hemlock (Tsuga canadensis) formed the primary cover type (Pastor and Broschart 1990, White and Mladenoff 1994). After being selectively harvested for white pine in the mid1800 s, hemlock-northern hardwood forests were mostly cut over by the 1920s (Whitney 1994). Most of this forest landscape is now dominated by second-growth hardwoods (White and Mladenoff 1994). Hemlock remains a common community element in the few remaining primary forests on mesic sites (Curtis 1959, Frelich et al. 1993, Mladenoff et al. 1993, Tyrrell and Crow 1994, White and Mladenoff 1994), and has since partially rebounded in some lowland and riparian areas. However, hemlock remains uncommon in previously logged, upland stands. In the northern Great Lakes region, hemlock forest cover types presently occupy only $0.5 \%$ of the upland landscape (Mladenoff and Stearns 


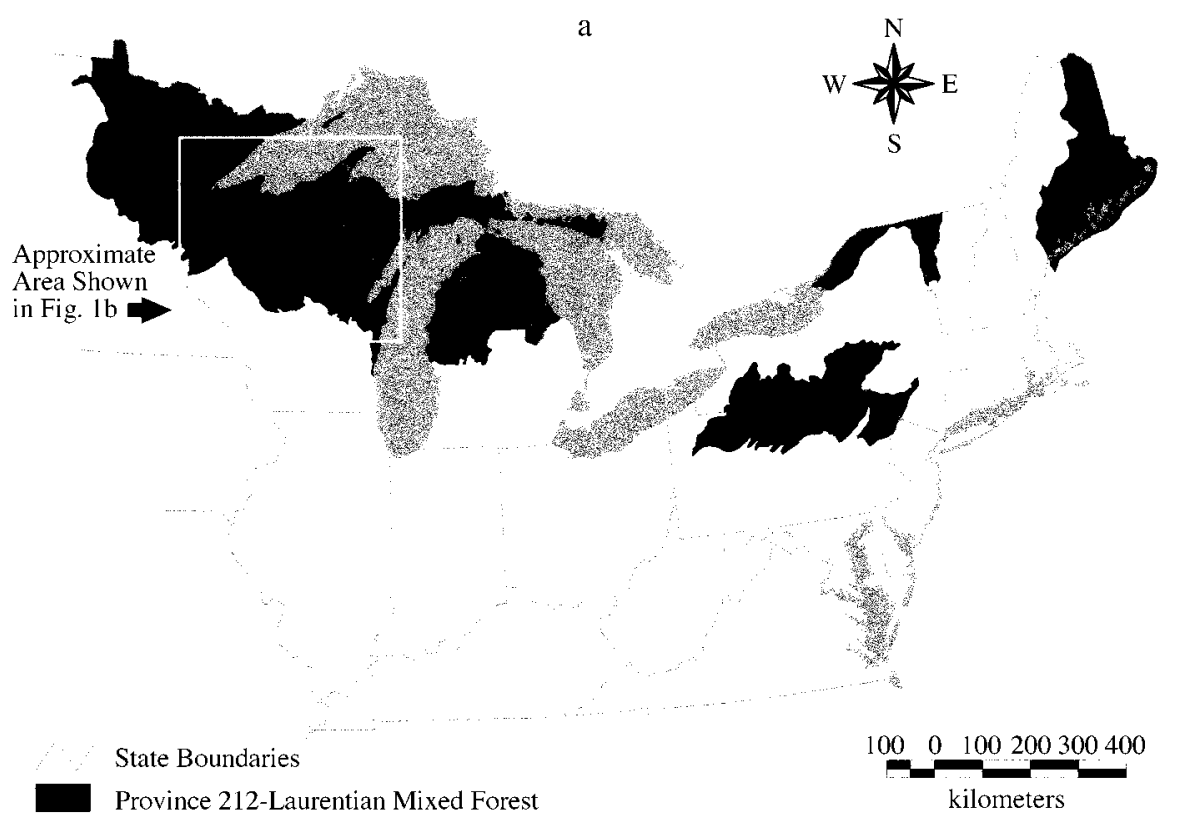

b

State Borders

- Study Site Locations

$\sim$ Southern Superior Uplands

Boundary (Section 212J)

Subsection Boundaries

Surrounding Subsections

Study Site Subsections

LSCP = Lake Superior Clay Plain (212Ja)

GPIR = Gogebic/Penokee Iron Range $(212 J \mathrm{~J})$

$\mathrm{WM}=$ Winegar Moraine (212Je)

$\mathrm{GBM}=$ Green Bay Moraine $(212 \mathrm{Jj})$

$B P R M=$ Brule and Paint Rivers Moraine (212Jl)

$\mathrm{NHPO}=$ Northern Highlands Pitted Outwash $(212 \mathrm{Jm})$

FIG. 1. (a) Province 212, the Laurentian Mixed Forest, in the United States; and (b) Section 212J, the Southern Superior Uplands in Wisconsin and Michigan. Dots indicate study sites. Map units follow Keys et al. (1995).

1993; see also Abrams and Ruffner 1995). Restoration of hemlock-dominated landscape elements is being considered by federal land management agencies (Crow et al. 1994), but significant barriers to landscapelevel hemlock restoration exist. First and foremost, the replacement of hemlock by hardwoods has decreased the habitat suitability for hemlock seedling establishment (Frelich et al. 1993, Mladenoff and Stearns 1993,
Davis et al. 1996). Second, while hemlock is highly shade tolerant and maintains an understory sapling bank, recruitment within remaining hemlock stands may not be sufficient to maintain the cover type where it currently persists. This study addresses the second and more immediate problem.

In both primary and secondary forest stands where hemlock remains a major canopy component, hemlock 
seedlings and saplings are often rare or absent (Graham 1941, Maissurow 1941, Frelich and Lorimer 1985). In their regional study of hemlock seedling establishment, Rooney and Waller (1998) found that most hemlock stands typically had fewer than 1000 seedlings/ha (4$29 \mathrm{~cm}$ tall), and seedlings were highly clumped spatially. These stands would be classified by foresters as poorly stocked with seedlings. Given that established hemlock stands in the Southern Superior Uplands Section were self-perpetuating for the past 3000 years in the absence of fire, and many hemlock stands now appear to be shifting in composition toward hardwoods, it is highly likely that hemlock seedling densities are lower than they were a century ago (Frelich and Lorimer 1985, Frelich and Reich 1995, Davis et al. 1996).

Several hypotheses have been proposed to account for poor regeneration in hemlock. Within stands, seedling establishment may be limited by the availability of appropriate microsite conditions (e.g., moss beds, nurse $\log$ s, or bare mineral soil, Stearns 1947, Goder 1961, Rooney and Waller 1998). Alternatively, hemlock seedlings may be limited by moisture availability (Graham 1941, Hough and Forbes 1943, Stearns 1947, Coffman 1978), soil characteristics (Rogers 1978, Pastor and Mladenoff 1992), or other habitat features (Kotar 1996). Foresters often prescribe fire or scarification to improve seedbed conditions (Maissurow 1941, Pubanz 1996). The widespread replacement of natural disturbance regimes by short-rotation timber management may have eliminated rotting $\log$, pit and mound topography, or some other more cryptic but essential habitat feature needed for successful hemlock establishment (Alverson et al. 1994, Rooney 1995, Rooney and Dress 1997, Rooney and Waller 1998).

Because they grow slowly and provide winter browse, hemlock seedlings are also sensitive to herbivory by white-tailed deer (Curtis 1959, Hough 1965 , Anderson and Loucks 1979, Frelich and Lorimer 1985, Alverson et al. 1988, Waller et al. 1996, Alverson and Waller 1997). Deer especially affect many plant species in eastern and midwestern forests and may act as a "keystone" herbivore, greatly altering forest composition and community structure (McShea and Rappole 1992, Waller and Alverson 1997).

The processes responsible for the poor tree seedling recruitment remain obscure in many cases because most studies focus on fine spatial scales, single causal variables, and/or only one stage of development (Clark et al. 1999). James et al. (1997) introduced the method of "species-centered environmental analysis" to determine the relative importance of various biotic and abiotic factors that potentially limit populations. We used this approach to examine factors which significantly contributed to variation in hemlock seedling and sapling densities at 100 sites throughout the Southern Superior Uplands Section of the Laurentian Mixed Forest Province of the United States (Keys et al. 1995). At each study site, we recorded data on multiple site factors that could influence hemlock recruitment as well as the abundance of hemlock seedlings and saplings. We used four successive demographic size classes to distinguish among factors that affect differentsized seedlings, and define recruitment as the progression of individuals from one size class to the next.

\section{Species And Seedling Biology}

Eastern hemlock is a long-lived, shade-tolerant conifer occurring on moist, acidic soils in mesic forests (Curtis 1959). Until 120 years ago, this conifer occurred as a dominant and codominant across the hemlockwhite pine-northern hardwoods region of the northern and northeastern United States (Nichols 1935). This forest region extends from northeastern Minnesota through the Great Lakes into southern Canada and New England and south into New York and Pennsylvania, with elements occurring at higher elevations in the central and southern Appalachians (Braun 1950). In the Upper Great Lakes, hemlock was an important element of the presettlement landscape for the past 3000 years (Davis 1987), where it co-occured with maple, basswood, and yellow birch (Braun 1950, Curtis 1959, Finley 1976). In the eastern portion of its range, American beech is a common associate (Braun 1950, Abrams and Ruffner 1995).

Hemlock occurs in thirteen forest types in the Great Lakes region (Fowells 1965), and is a major component in three of these: white pine-hemlock (Type 22), hemlock (Type 23), and hemlock-yellow birch (Type 24). On mesic, nutrient-poor sites with sandy loam and podzolized loam soils, hemlock is a canopy dominant in late-successional stands, with white pine and balsam fir being common associates. On the richer mesic sites with loams and sandy loams, hemlock may occur with northern hardwood species including red maple, sugar maple, and yellow birch (Willis and Coffman 1975, Kotar et al. 1988).

Canopy trees produce a large seed crop every two to three years (Hough 1960). Hemlock seeds require stratification, and will germinate on any moist substrate in the spring following dispersal (Curtis 1959, Hough 1960). Seedlings are highly susceptible to desiccation, and thus are most likely to become established on moist substrates such as nurse logs or moss beds (Goder 1961, Rooney and Waller 1998). Abundance of seedlings $<10$ $\mathrm{cm}$ tall is highest on coarse woody debris (Goder 1961), and is (weakly) positively correlated with light levels (Waller et al. 1996). Recruitment of seedlings into larger size classes tends to be highest for seedlings occupying tip-up mounds or well-decayed logs (Goder 1961). Where white-tailed deer densities are high, browsing further limits recruitment by killing saplings (Anderson and Loucks 1979, Frelich and Lorimer 1985, Alverson et al. 1988, Waller et al. 1996). Saplings generally undergo multiple cycles of suppression and release before reaching the canopy (Stearns 1947, Frelich and Graumlich 1994). While even-aged stands of hem- 
lock do occur (Hough and Forbes 1943), most unmanaged stands examined show a negative exponential (Goff and West 1975) or negative sigmoidal (Hett and Loucks 1976) size structure, indicating most stands have an uneven-aged structure (Frelich and Lorimer 1991).

\section{Materials And Methods}

This study grew out of work done in the early 1990s that examined the role of white-tailed deer browsing in limiting hemlock recruitment (Waller et al. 1996). The sites sampled were selected using a stratified (by land ownership category) random sampling procedure from lists of hemlock stands (see Waller et al. 1996 for additional details). These ownerships differed in both deer management goals and deer densities, but all contained hemlock forest types. Sites were selected without any prior knowledge of hemlock recruitment. Rather than choose a few sites for intensive studies, we chose a large number of sites and conducted a geographically extensive survey. By doing so, we could average over local variation due to disturbance history, hunter activity, distance from winter deer yards, and other local nuances, and so explore robust regional patterns of hemlock seedling recruitment.

To assess regional variation in recruitment success, we surveyed 100 hemlock stands in the Southern Superior Uplands Section (Keys et al. 1995) of northern Wisconsin and the upper peninsula of Michigan during the summer of 1996. These sites are a geographically central subset of the 145 sites initially surveyed in 1990 by Waller et al. (1996). Sites were distributed across a broad area $\left(\sim 15000 \mathrm{~km}^{2}\right)$ and among many land owners (county, state, and national forests, national lakeshore, Indian reservations, and private lands) in an effort to provide extensive regional data on the extent of hemlock establishment and recruitment. We relocated the original marked quadrats whenever this was possible (at 64 out of 100 sites). We consider the 1996 data to be largely independent of the 1990 data we reported on in Waller et al. (1996), because these data were obtained six years later, and the sampling area in this study was three times larger.

\section{Demographic size classes}

We distinguished four demographic size classes for hemlock based on seedling height. We classified all plants between 4 and $9 \mathrm{~cm}$ tall as "seedlings," those from 10 to $29 \mathrm{~cm}$ as "small saplings," those from 30 to $99 \mathrm{~cm}$ as "medium-sized saplings," and those from 100 to $300 \mathrm{~cm}$ as "large saplings." We used size classes in preference to age classes for several reasons. First, because growth and mortality in plants usually depends more on size than age, size-based demographic models are more accurate than age-based models, particularly in species like hemlock where size and age are not strongly correlated (Harper 1977, Caswell 1989, Rooney and Waller 1998). Second, limiting factors change as plants grow larger, but not necessarily as they grow older. For example, meadow voles may kill short hemlock seedlings, but not larger plants (Ostfeld and Canham 1993). In contrast, white-tailed deer attack taller saplings rather than seedlings (Waller et al. 1996). As the height of 16-yr-old hemlocks can vary threefold (Rooney and Waller 1998), plants of identical ages but different sizes likely face distinct limiting factors. Finally, because most sites had few seedlings, we could not justify the use of destructive sampling procedures to age plants.

\section{Field methods}

At each site, we randomly placed a single $14 \times 21$ $\mathrm{m}$ quadrat consisting of six contiguous $7 \times 7 \mathrm{~m}$ subquadrats arranged in a $2 \times 3 \mathrm{~m}$ rectangle. Our quadrat size corresponds to that used by Kotar et al. (1988) to classify habitats (see below). Quadrats of this size are also necessary to ensure a high likelihood of detecting seedlings when these are sparse and patchy (Rooney and Waller 1998). Because of the patchy spatial distribution of hemlock seedlings, the use of smaller sampling quadrats is prone to less accurate estimates of seedling abundance. In each $7 \times 7 \mathrm{~m}$ subquadrat, we counted all the hemlock seedlings $4-9 \mathrm{~cm}$ tall, and counted and measured the height of all hemlock saplings between 10 and $300 \mathrm{~cm}$ tall.

We examined many local and regional factors thought to play a role in hemlock establishment and recruitment (Table 1). At the subquadrat level, we recorded leaf litter type, depth, and light availability. We categorized the type of leaf litter cover based on visual inspection. We classified litter type as needle if $>75 \%$ of the subquadrat was covered with needle litter, broadleaved if $>75 \%$ was covered with broad-leaved litter, or mixed in all other cases. Nitrogen mineralization rates tend to be higher in areas with broad-leaved litter, which gives deciduous species a competitive advantage over hemlock (Pastor and Mladenoff 1992, Mladenoff and Stearns 1993). We measured the depth of litter to the nearest $0.5 \mathrm{~cm}$ at one to three random points in each subquadrat using a steel ruler to test the hypothesis that since hemlock seedling radicles have difficulty penetrating deep litter, litter depth may limit seedling establishment. We determined incident light levels by measuring the percentage of open canopy $1.5 \mathrm{~m}$ above each subquadrat by recording vertical canopy images with a "HI-8" video camera (Sony TR700, Sony, Tokyo) set to the widest angle zoom setting and equipped with a wide angle accessory lens to encompass a broad field $\left(\sim 90^{\circ}\right)$. Exposure was set manually to fit the brightness of the open sky in large canopy openings. Still frames $(480 \times 640$ pixels $)$ for each subquadrat were subsequently digitized using a Macintosh computer equipped with a video capture card. These images were analyzed in a pixel-based image analysis program (Adobe Photoshop, San Jose, California, USA) by lightening all sky pixels to white and darkening canopy 
TABLE 1. Variables hypothesized to affect (A) hemlock seedling establishment and (B) recruitment into larger size classes.

\begin{tabular}{|c|c|}
\hline Variable & Quantification \\
\hline \multicolumn{2}{|c|}{ A) Seedling Establishment } \\
\hline Seed input & $\begin{array}{l}\text { Estimated to be proportional to the hemlock tree basal area, which was determined by sum- } \\
\text { ming hemlock stem areas over the quadrat estimated from dbh measurements }\end{array}$ \\
\hline Litter type & The major constituent of leaf litter (needle, broadleaf, or mixed needle/broadleaf) \\
\hline Litter depth & The depth of leaf litter (to nearest $0.5 \mathrm{~cm}$ ) \\
\hline Light & $\begin{array}{l}\text { The percentage of open canopy above each subquadrat, as estimated via analysis of canopy } \\
\text { video images }\end{array}$ \\
\hline Habitat type & $\begin{array}{l}\text { Forest site classification based on inferred edaphic properties based on measured understory } \\
\text { vegetation (see Table } 2 \text { ) }\end{array}$ \\
\hline Microhabitat & $\begin{array}{l}\text { Coarse woody debris, tip-up mounds, and forest floor sites where seedlings establish. Exam- } \\
\text { ined in Rooney and Waller (1998); not this study }\end{array}$ \\
\hline Subsection & Ecological subsections, see Table 3 \\
\hline \multicolumn{2}{|l|}{ B) Recruitment } \\
\hline Habitat type & (see above) \\
\hline Light & (see above) \\
\hline Browse & $\begin{array}{l}\text { Index of local browsing pressure equal to the proportion of terminal twigs of sugar maple } \\
\text { between } 30-200 \mathrm{~cm} \text { high that are browsed (Frelich and Lorimer 1985) }\end{array}$ \\
\hline Subsection & (see above) \\
\hline Demography & $\begin{array}{l}\text { Number of seedlings or saplings in preceding size class }(4-9,10-29,30-99 \text {, and } 100-300 \\
\mathrm{cm} \text { tall) }\end{array}$ \\
\hline
\end{tabular}

foliage, trees, and other obstructions to black. The ratio of white to total (black + white) pixels provides an estimate of percentage open canopy above the subquadrat.

At the quadrat level, we recorded the basal area of all trees $>2.5 \mathrm{~cm}$ diameter at breast height ( $\mathrm{dbh}$ ), habitat type, and deer browsing intensity. We used the basal area of hemlock as a surrogate for seed input. We examined the vegetation within quadrats and classified the habitat following the Field Guide to Forest Habitat Types of Northern Wisconsin (Kotar et al. 1988). Habitat types are based largely on soil moisture capacity and nutrient content, and can be used to determine the potential forest cover type and management potential of any particular site (Table 2). We surveyed deer browsing damage using a sugar maple (Acer saccharum) browse index. This index measures local deer browsing pressure, and is conducted by counting the number of browsed and unbrowsed terminal twigs 30$200 \mathrm{~cm}$ above the ground. The ratio of browsed to total twigs sampled provides a measure of browsing intensity on a scale from 0 to 1 (after Frelich and Lorimer 1985). Since size-structured populations exhibit demographic momentum (Caswell 1989), we included the number of hemlocks in the preceding size class as a predictor variable of the number of hemlocks in the size class of interest.

Site locations were mapped to assess the effects of geography and land owner on recruitment. Ecosystems can be classified at many spatial scales based on homogenous properties at a particular scale. For example, climate determines the distribution of biomes at a global scale, whereas soils and topography determine the distribution of cover types at a spatial scale of thousands of hectares in glaciated landscapes (Bailey 1996). If the units of hierarchical ecological classification systems are to be useful, they need to correspond to spatial scales at which ecological phenomena occur, and delineate regions that organisms recognize (Rykken et al. 1997). All of our study sites occur in six of the 17 subsections nested within the Section 212J, the Southern Superior Uplands (Keys et al. 1995; Table 3). These six subsections each cover tens of thousands of hectares, and each is internally homogenous with respect to bedrock geology, glacial deposits, soil taxa, and consequently, potential vegetation. We tested the hypothesis that the abundance of hemlock recruitment would differ among subsections. Land owner affects hemlock recruitment indirectly via different forest management objectives. In addition, deer management goals differ

TABLE 2. Habitat types (with abbreviations) and their inferred physical and biological characteristics.

\begin{tabular}{llll}
\hline \hline \multicolumn{1}{c}{ Habitat type name } & Moisture status & Nutrient status & Potential forest cover types \\
\hline Tsuga-Maianthemum-Coptis $(\mathrm{TMC})$ & mesic to wet mesic & low to medium & hemlock-maple-birch \\
Acer-Tsuga-Maianthemum (ATM) & dry mesic to mesic & medium & hemlock-maple-birch \\
Acer-Tsuga-Dryopteris (ATD) & dry mesic to mesic & medium to rich & hemlock-maple-birch \\
Acer-Fagus-Dryopteris (AFD) & dry mesic to mesic & medium to rich & beech-hemlock-maple-birch \\
Acer-Viola-Osmorhiza (AViO) & mesic & rich & maple \\
\hline
\end{tabular}

Notes: These habitat types are based on observed vegetation and indicator species, are one hectare to tens of hectares in size, and are not part of a hierarchical classification scheme. Habitat types follow Kotar et al. (1988). 
TABLE 3. Ecological subsections (with abbreviations) and their physical and biological characteristics.

\begin{tabular}{|c|c|c|c|}
\hline Subsection & Geomorphology & Soils & Potential forest cover types \\
\hline $\begin{array}{l}\text { Lake Superior Clay Plain } \\
\text { (LSCP) }\end{array}$ & $\begin{array}{l}\text { level plains till over Pre- } \\
\text { cambrian sandstone bed- } \\
\text { rock }\end{array}$ & $\begin{array}{l}\text { sand and clay loams, out- } \\
\text { wash sand and gravel }\end{array}$ & $\begin{array}{l}\text { white pine-red pine, } \\
\text { spruce-fir, aspen-birch }\end{array}$ \\
\hline $\begin{array}{l}\text { Gogebic/Penokee Iron } \\
\text { Range (GPIR) }\end{array}$ & $\begin{array}{l}\text { think glacial till over basalt- } \\
\text { conglomerate bedrock }\end{array}$ & $\begin{array}{l}\text { sandy loams, ice-contact } \\
\text { outwash sand and gravel }\end{array}$ & $\begin{array}{l}\text { maple-basswood, hemlock- } \\
\text { maple }\end{array}$ \\
\hline Winegar Moraines (WM) & $\begin{array}{l}\text { ice stagnated features over } \\
\text { metamorphic bedrock }\end{array}$ & $\begin{array}{l}\text { sandy loams, outwash sand- } \\
\text { gravel }\end{array}$ & $\begin{array}{l}\text { maple-basswood, hemlock- } \\
\text { maple }\end{array}$ \\
\hline $\begin{array}{l}\text { Green Bay Lobe Stagnation } \\
\text { Moraine (GBM) }\end{array}$ & $\begin{array}{l}\text { irregular moraines over Pre- } \\
\text { cambrian bedrock }\end{array}$ & $\begin{array}{l}\text { ice contract-outwash sand- } \\
\text { gravel, sandy loam till }\end{array}$ & hemlock-maple \\
\hline $\begin{array}{l}\text { Brule and Paint Rivers } \\
\text { Drumlinized Ground Mo- } \\
\text { raine (BPRM) }\end{array}$ & $\begin{array}{l}\text { rolling drumlins over Pre- } \\
\text { cambrian basalt and gran- } \\
\text { ite }\end{array}$ & $\begin{array}{l}\text { ice contact-outwash sand- } \\
\text { gravel, sandy loams }\end{array}$ & $\begin{array}{l}\text { maple-basswood, hemlock- } \\
\text { maple }\end{array}$ \\
\hline $\begin{array}{l}\text { Northern Highlands Pitted } \\
\text { Outwash (NHPO) }\end{array}$ & $\begin{array}{l}\text { rolling to steep depressional } \\
\text { sands over Precambrian } \\
\text { mafic-felsic-metavolcanic- } \\
\text { quartzite }\end{array}$ & $\begin{array}{l}\text { sandy loams, outwash sand- } \\
\text { gravel }\end{array}$ & $\begin{array}{l}\text { white pine-red pine, maple- } \\
\text { basswood }\end{array}$ \\
\hline
\end{tabular}

Notes: These subsections are thousands to tens of thousands of square kilometers in size and are hierarchically nested within the Southern Superior Uplands Section, where this study was conducted. Ecological subsections follow Keys et al. (1995).

among ownerships and are under local, autonomous control on the two Indian reservations in this study (Menominee and Lac du Flambeau). Deer populations are lower on reservations than elsewhere in the state (Vander Zouwen and Warnke 1995, Waller et al. 1996). Throughout the rest of Wisconsin and Michigan, the states maintain jurisdiction over setting local deer density goals.

\section{Data analysis}

To summarize patterns of hemlock seedling and sapling densities among sites, we established three density classes: <100 stems/ha, 100-10000 stems/ha, and $>10000$ stems/ha. We examined the proportion of sites having these densities for each hemlock size class as follows. Forest canopy composition was recorded for each density class. Hemlock, sugar maple, yellow birch (Betula alleghaniensis), and balsam fir (Abies balsamea) comprised $>90 \%$ of the total basal area we surveyed. We standardized the total basal area of these four species to $100 \%$ at each site, and determined the proportion of basal area of each species for each of the three hemlock seedlings density classes. We used a oneway ANOVA to determine if the proportional basal area of each species differed among seedling density classes, and used Tukey's B procedure to separate means. Groups were considered significantly different when $P$ $<0.05$.

We analyzed recruitment data in the following hierarchical fashion. First, we examined the individual relationships between each predictor variable listed in Table 1 and the abundance of hemlock in each of the four hemlock size classes. We used one-way analysis of variance to test for differences among classes of the categorical variables, and least squares regression to examine relationships with continuously distributed variables. We natural log-transformed the abundance of hemlock in each size class to satisfy the assumptions for parametric tests. Regressions were plotted to check that predictor variables had linear effects. Significant results indicate that predictor variables are important determinants of hemlock abundance throughout the region, and not merely at some sites.

Next, we used a multivariate approach to disentangle the effects of multiple factors influencing hemlock abundance. All predictor variables that were significant at the $P<0.05$ level in univariate analyses were used to construct a path analysis model. This technique succinctly combines multiple causal relationships, summarizing how direct and indirect effects combine to influence logically successive dependent variables $(\mathrm{Li}$ 1975, Sokal and Rohlf 1981). The standardized partial regression coefficients (path coefficients) used in the model were determined by building a general linear model that described the factors responsible for variation in the abundance of each hemlock size class in a quadrat (i.e., $14 \times 21 \mathrm{~m}$ ). Variables were eliminated from each model using a backward elimination procedure to remove variables that were not significant in the combined model at the 0.05 level (Wilkinson et al. 1996). Although all variables were significant in the univariate models, collinearities among some variables resulted in low partial correlations with hemlock abundance and consequently they were removed from the multivariate model. This procedure resulted in models for each demographic size class that indicated the relative and combined importance of particular predictor variables in accounting for variation in local hemlock abundance. Because data on canopy openness and leaf litter type were collected at the subquadrat level, we incorporated light into the general linear model by averaging the percentage open canopy from all six subquads. We were unable to include leaf litter type data in the model, however, as this independent variable is categorical and often varied among subquadrats. Because leaf litter type only explained a little of the local 


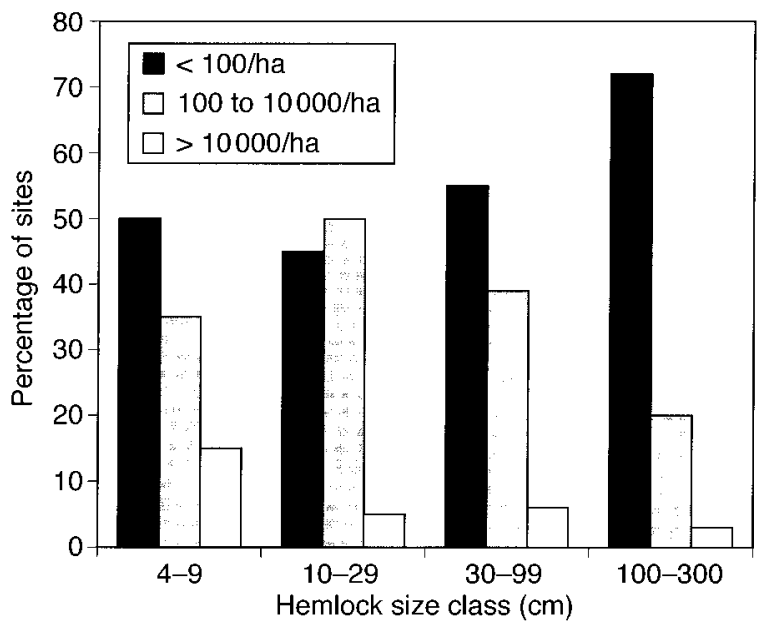

FIG. 2. The percentage of sites containing $<100$ hemlock individuals/ha (black bars), 100-10 000 hemlock individuals/ ha ( shaded bars), and $>10000$ hemlock individuals/ha (open bars) in each of the four size classes. Percentages add up to $100 \%$ in each size class.

and regional variation in hemlock abundance (see $R e$ sults), its absence from the model is unlikely to affect the results or interpretation. For categorical variables, we estimated the path coefficients from the square root of the proportion of the variance $\left(r^{2}\right)$ accounted for in the general linear model. Because land owner directly affects deer density and therefore hemlock abundance indirectly (Waller et al. 1996), we included land owner as a categorical variable through this effect in the path analysis model. We also examined the relationship between ecological subsection and deer browse.

Path analysis makes three assumptions: (1) that the variables can be placed into an unambiguous causal order, (2) that effects are linear, and (3) that effects of different predictor variables are additive. As recruitment into each successive size class necessarily depends on the presence of smaller seedlings or saplings, and as environmental variables clearly affect small hemlocks (but not vice versa), the causal order assumption is met. Similarly, the log transformations sufficed to linearize relationships between predictor and dependent variables. Finally, we failed to detect any significant interaction terms in the general linear model.

\section{RESUlts}

Hemlock individuals in all size classes were not particularly abundant. More than $40 \%$ of the sites had fewer than 100 individuals/ha in all size classes, and large saplings were particularly sparse (Fig. 2). Sites with $>10000$ seedlings/ha tended to have a higher relative proportion of hemlock basal area (one-way ANOVA, df $=2,97, F=4.29, P=0.01$; Fig. 3 ). The relative proportions of sugar maple, yellow birch, and balsam fir basal area, however, did not vary among sites with varying densities of hemlock seedlings. Hemlock seedlings and saplings were completely absent from $8 \%$ of the sites. Twenty percent of the sites had only one size class present, $20 \%$ had two size classes, $31 \%$ had three size classes, and $21 \%$ had all four size classes present. In all, we found 1543 hemlock seedlings for an average density of 525 seedlings/ha in these hemlock stands.

The abundance of hemlock seedlings (4-9 $\mathrm{cm}$ tall) appears related to leaf litter type and light availability, each of which account for a highly significant but small amount of the total regional variance in seedling numbers (Table 4). Hemlock seedlings were almost twice as abundant in subquadrats containing needle leaf litter than in subquadrats with leaf litter classified as mixed or broad-leaved. Seedling numbers in mixed and broadleaved litter did not significantly differ. Seedling abundances were higher in subquadrats with higher light levels. The relationship between seedling abundance and light availability was weak but linear. However, $>60 \%$ of the sites examined had $<20 \%$ open sky above the quadrat. Seedling numbers also significantly differed among ecological subsections. The Green Bay Lobe Stagnation Moraine (GBM) had significantly more seedlings than the Brule and Paint Rivers Drumlinized Ground Moraine (BPRM) and Lake Superior Clay Plain (LSCP) ecological subsections (Table 3, Fig. 4a). Leaf litter depth, seed input, browsing intensity, and habitat type showed no significant effects on seedling abundance.

The number of hemlocks in the small $(10-29 \mathrm{~cm}$ tall) saplings size class depended on the number of seedlings present at each site, ecological subsection, and, to a lesser extent, light availability (Table 4, Fig. $4 \mathrm{~b})$. The abundance of small saplings increased linearly in areas with more seedlings and higher light avail-

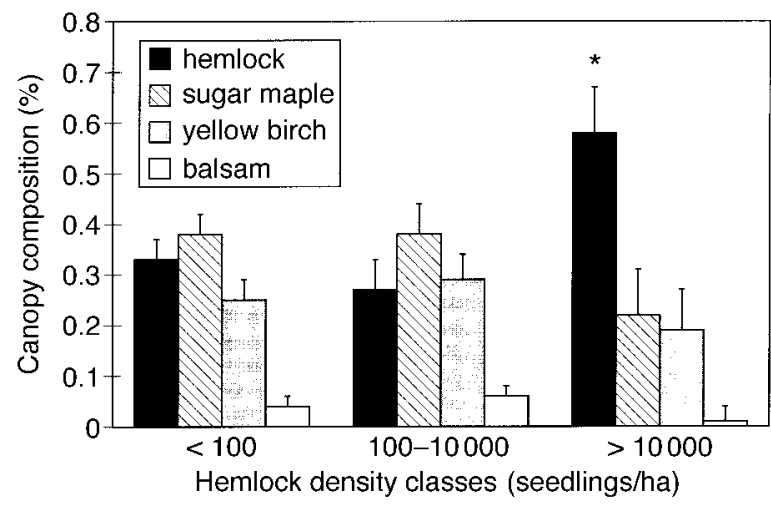

FIG. 3. The relative abundance, measured as the relative proportion of basal area within stands $(+1 \mathrm{SE})$, of the four most abundant canopy species in the 100 quadrats, for each of three hemlock seedling abundance classes. Relative hemlock basal area is greater on sites with $>10000$ hemlock seedlings/ha than sites with lower seedling densities. The asterisk denotes significance at $P<0.05$ using Tukey's B procedure. 
TABLE 4. Variables hypothesized to account for regional variation in the abundance of hemlock seedlings and saplings, analyzed at the level of the subquadrat or quadrat.

\begin{tabular}{|c|c|c|c|c|c|c|}
\hline Hemlock size class & $\begin{array}{l}\text { Spatial resolution } \\
\text { of analysis }\end{array}$ & Variable name & df & $F$ & $P$ & $r^{2}$ \\
\hline \multirow[t]{7}{*}{ Seedling $(4-9 \mathrm{~cm})$} & \multirow[t]{3}{*}{ subquadrat } & litter type & 2,553 & 14.92 & $<0.001$ & 0.048 \\
\hline & & litter depth & 1,555 & 0.95 & 0.33 & $\ldots$ \\
\hline & & light & 1,555 & 11.26 & 0.001 & 0.020 \\
\hline & \multirow[t]{4}{*}{ quadrat } & subsection & 5,88 & 4.32 & 0.002 & 0.197 \\
\hline & & habitat type & 4,95 & 0.49 & 0.74 & $\ldots$ \\
\hline & & basal area & 1,81 & 0.47 & 0.50 & $\cdots$ \\
\hline & & browse & 1,98 & 1.55 & 0.22 & $\cdots$ \\
\hline \multirow[t]{6}{*}{ Small sapling $(10-29 \mathrm{~cm})$} & subquadrat & light & 1,552 & 25.06 & $<0.001$ & 0.043 \\
\hline & \multirow[t]{5}{*}{ quadrat } & subsection & 5,88 & 4.72 & $<0.001$ & 0.211 \\
\hline & & habitat type & 4,95 & 2.03 & 0.10 & $\cdots$ \\
\hline & & basal area & 1,81 & 0.03 & 0.86 & $\ldots$ \\
\hline & & browse & 1,98 & 0.41 & 0.52 & $\cdots$ \\
\hline & & (ln) seedlings & 1,98 & 72.85 & $<0.001$ & 0.426 \\
\hline \multirow{6}{*}{ Medium sapling $(30-99 \mathrm{~cm})$} & \multirow{6}{*}{$\begin{array}{l}\text { subquadrat } \\
\text { quadrat }\end{array}$} & light & 1,552 & 29.83 & $<0.001$ & 0.050 \\
\hline & & subsection & 5,88 & 8.85 & $<0.001$ & 0.335 \\
\hline & & habitat type & 4,95 & 1.52 & 0.20 & $\ldots$ \\
\hline & & basal area & 1,81 & 0.02 & 0.91 & $\cdots$ \\
\hline & & browse & 1,98 & 9.81 & 0.004 & 0.083 \\
\hline & & (ln) small saplings & 1,98 & 89.03 & $<0.001$ & 0.476 \\
\hline \multirow[t]{6}{*}{ Large sapling $(100-300 \mathrm{~cm})$} & subquadrat & light & 1,552 & 10.30 & 0.001 & 0.018 \\
\hline & quadrat & subsection & 5,88 & 5.84 & $<0.001$ & 0.249 \\
\hline & & habitat type & 4,95 & 0.65 & 0.63 & $\cdots$ \\
\hline & & basal area & 1,81 & 0.29 & 0.59 & $\cdots$ \\
\hline & & browse & 1,98 & 3.67 & 0.05 & 0.038 \\
\hline & & (ln) med. saplings & 1,98 & 85.89 & $<0.001$ & 0.467 \\
\hline
\end{tabular}

Notes: Each result is derived from a separate univariate test (one-way ANOVA or regression). The abundance of hemlocks in all size classes was natural log-transformed prior to analysis to meet assumptions of normality and homogeneity of variances.

ability, as expected, and showed no statistical relationship with either habitat type, seed input, or browsing pressure. Small saplings were most abundant in the Northern Highland Pitted Outwash (NHPO) subsection, and least abundant in the BPRM subsection (Fig. 4b).

The number of hemlocks in the medium-sized (30$99 \mathrm{~cm}$ tall) sapling size class increased in parallel with the number of individuals in the small sapling size class. The abundance of medium-sized saplings was also positively correlated with higher light levels, and varied significantly among subsections, with more in the NHPO, and less in the BPRM and LSCP (Table 4, Fig. 4c). Medium-sized saplings also declined conspicuously in abundance as browsing pressure increased (Table 4, Fig. 5). The abundance of saplings in this size class were unaffected by hemlock seed input and habitat type.

The number of saplings in the large $(100-300 \mathrm{~cm}$ tall) sapling size class present at a site was positively related to the abundance of medium-sized saplings and light levels and negatively related to browsing pressure (Table 4). Subsection again accounted for a significant fraction of the regional variation in large sapling abundance with no large saplings occurring in either the BPRM or LSCP. Most of the large saplings were found in the NHPO (Fig. 4d). Habitat type and seed input are unrelated to the abundance of large saplings, as with all other demographic size classes.

Path analysis allows us to combine and simplify the several factors that together affect the abundance of each demographic size class, improving overall predictive power (Table 5, Fig. 6). As seen in the univariate analyses, geography and light levels affect the abundance of seedlings and small saplings. The path analysis, however, reveals that light and ecological subsection do not directly affect the abundances of medium and large saplings despite being highly significant in the univariate analyses. Rather, they achieve their significant correlations via the indirect effects they have through the abundance of smaller seedlings. Such indirect effects influence all the larger size classes. Thus, while indirect effects are absent from the analysis of seedling numbers and only account for $6.4 \%$ of the variance in small sapling numbers, they account for $27.5 \%$ and $34.9 \%$ of the variance in medium and large sapling numbers, respectively. The combined direct and indirect effects of light, ecological subsection, browse pressure, and demographic population structure explain $24.1 \%$ of the regional variation in seedling abundance, $63.4 \%$ of the variation in small sapling abundance, $78.9 \%$ of the variation in medium sapling abundance, and $81.6 \%$ of the variation in large sapling abundance. When considered individually, both ecological subsection $(r=0.61)$ and land owner $(r=0.72)$ had a significant effect on browsing pressure. When considered together, however, only land owner remained significant. Since all the assumptions are met, this path analysis model serves as a concise summary of the ecological factors affecting regional variation in hemlock recruitment. 

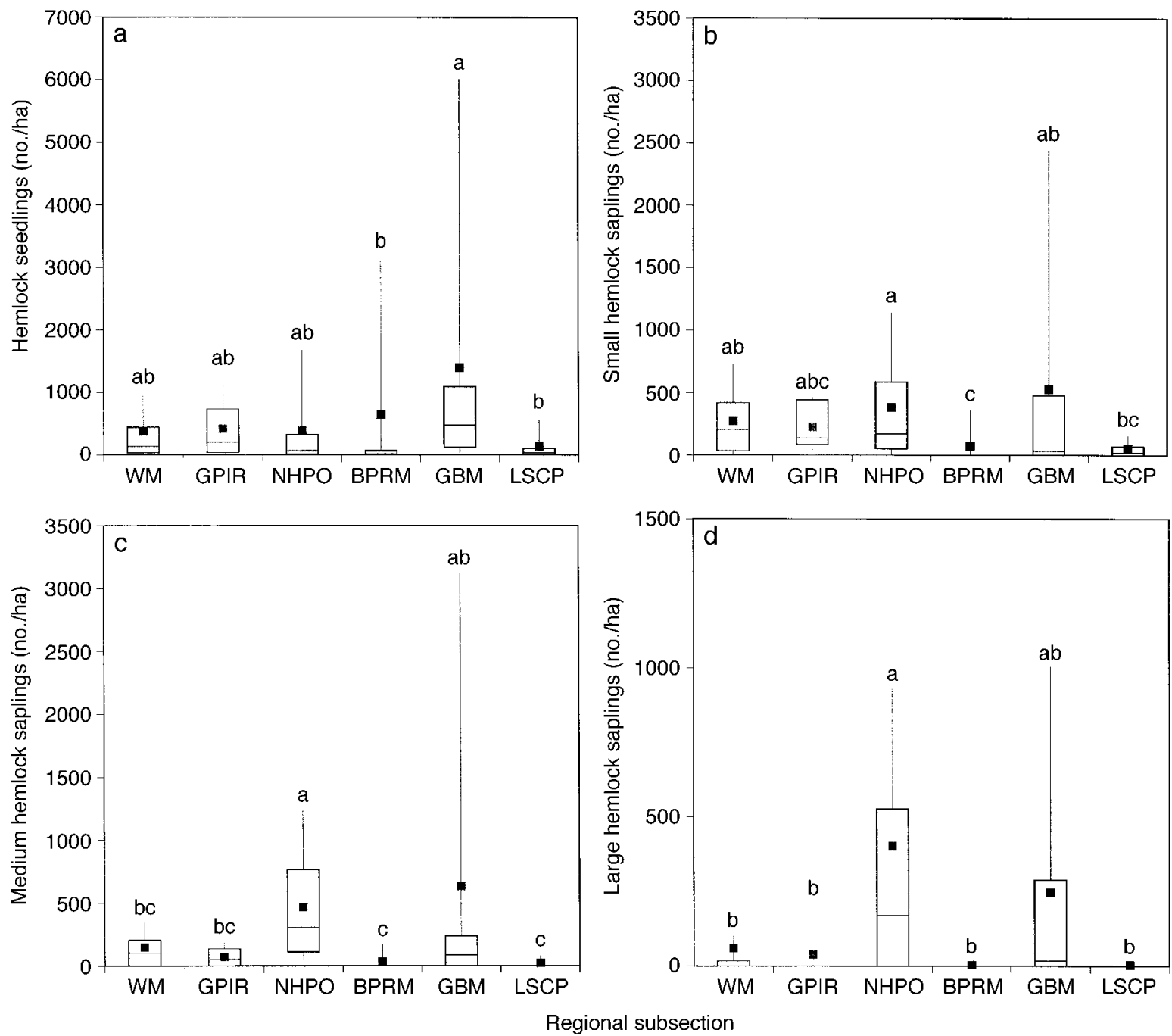

FIG. 4. The number of hemlock individuals per site across subsections, for (a) seedlings, (b) small saplings, (c) medium saplings, and (d) large saplings. Squares represent means; the center lines in the boxes represent medians; boxes extend from the 25 th to the 75 th percentile, and whiskers extend from the 10th to the 90th percentile. Subsections with different letters indicate a significant difference at the 0.05 level using Tukey's B procedure. Abbreviations are as follows: WM $=$ Winegar Moraine; GPIR = Gogebic/Penokee Iron Range; NHPO = Northern Highlands Pitted Outwash; BPRM = Brule and Paint Rivers, Drumlinized Ground Moraine; GBM = Green Bay Lobe Stagnation Moraine; LSCP = Lake Superior Clay Plain.

\section{DISCUSSION}

The relative importance of a particular ecological process within a geographic area is often extrapolated from small-scale, geographically restricted studies (Clark et al. 1999). Extrapolation might be acceptable if the geographic area of interest was relatively uniform and adequately represented by the study sites. Unfortunately, ecological systems usually lack such uniformity. A regional ecological process is better understood by examining that process at multiple sites throughout the geographic area of interest (Underwood and Petraitis 1993). By doing so, researchers are able to distinguish between processes that are locally important from those that are regionally important. In this study, we examined many ecological factors previously stud- ied at small scales and invoked as explanations for regional patterns.

Many factors, considered individually, appear to account for significant variation in the abundance of hemlock seedlings and saplings. However, the multivariate analyses reveal that some of these factors are intercorrelated, and that only a few factors explain most of the regional variation in hemlock seedling and sapling abundance. Well designed, regional approaches have been used successfully by other researchers to examine ecological processes that were being extrapolated from local studies. Hecnar and M'Closkey (1996) examined amphibian species richness in Ontario, and concluded that geographically restricted observations of richness declines were also occurring regionally. However, local 


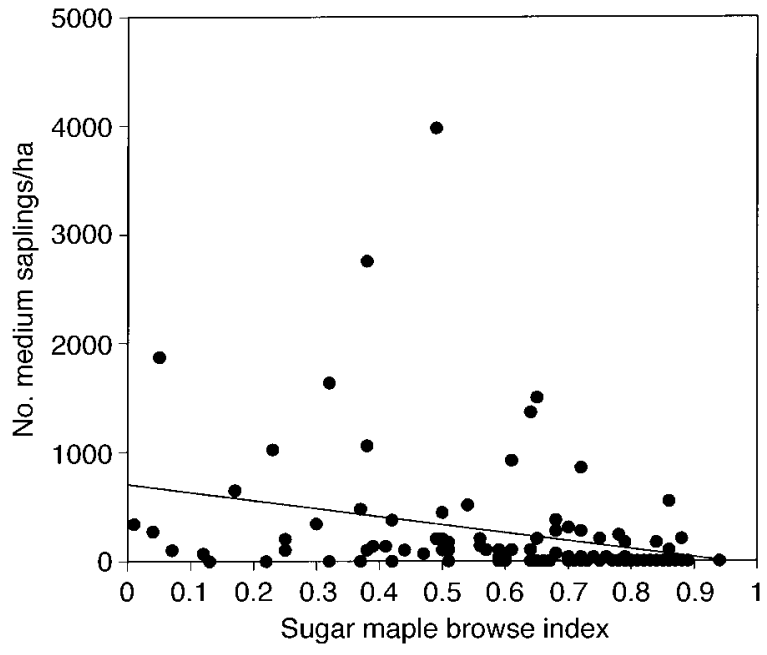

FIG. 5. The number of medium-sized hemlock saplings per hectare as a function of the sugar maple browsing index. The intercept and slope are both significant $(\ln$ (saplings) $=$ 2.06-1.58(browse); df $=1,98 ; r^{2}=0.083 ; P=0.004$ ).

patterns do not always hold up when examined regionally. In their study of migratory bird nesting success, Robinson et al. (1995) found that the overall degree of landscape fragmentation was a better predictor of nest predation than the area of the individual forest tract, despite the fact that previous small-scale studies had indicated that forest tract size was the determinant of nesting success (Wilcove 1985).
The abundance of hemlocks in each size class depends most strongly on the abundance of the immediately preceding size class. These path coefficients are remarkably consistent (0.61-0.68, Fig. 6) and account for from $37 \%$ to $46 \%$ of the total variation in the abundance of the three larger size classes. Such associations are expected, of course, due simply to demographic "momentum," the fact that saplings derive from smaller seedlings. If conditions remain relatively constant, we expect fewer saplings in sites with fewer small seedlings. Alternatively, the abundance of seedlings in succeeding size classes could be responding in tandem to some other variable(s). That is, variation in another unmeasured ecological factor could systematically favor, or hurt, hemlock seedlings of all sizes. While we attempted to identify and measure the most obvious and relevant environmental variables, others could exert significant effects that we are unaware of.

Two local abiotic variables, light and leaf litter type, affected seedling numbers. Hemlock abundance in all size classes was positively related to light availability, consistent with previous studies (Kobe 1996, Waller et al. 1996). Under heavy shade, the growth of hemlock slows. Despite its shade tolerance, hemlock becomes more susceptible to mortality from pathogens or herbivores as shade increases (Matson and Waring 1984). We also found that seedlings were twice as abundant at sites dominated by needle leaf litter than sites with broad-leaved litter or a mixture of needle and broadleaved litter. This could reflect higher seedling abun-

TABLE 5. Direct, indirect, and total effect of predictor variables on the number of individuals in each hemlock size class, as estimated via path analysis shown in Fig. 6.

\begin{tabular}{|c|c|c|c|c|}
\hline \multirow[b]{2}{*}{ Size class and variable } & \multicolumn{2}{|c|}{ Path coefficients } & \multirow{2}{*}{$\begin{array}{l}\text { Explained } \\
\text { variation }\end{array}$} & \multirow{2}{*}{$\begin{array}{c}\text { Total variance } \\
\text { explained } \dagger\end{array}$} \\
\hline & Direct effect & Indirect effect & & \\
\hline \multicolumn{5}{|l|}{ Seedling } \\
\hline Subsection & 0.415 & & 0.172 & \\
\hline \multirow[t]{2}{*}{ Light } & 0.262 & & 0.069 & \\
\hline & & & & 0.241 \\
\hline \multicolumn{5}{|l|}{ Small sapling } \\
\hline No. seedlings & 0.608 & & 0.370 & \\
\hline Subsection & 0.409 & & 0.167 & \\
\hline Light & 0.181 & & 0.033 & \\
\hline \multirow[t]{2}{*}{ Subsection $\rightarrow$ seedling } & & 0.252 & 0.064 & \\
\hline & & & & 0.634 \\
\hline \multicolumn{5}{|l|}{ Medium sapling } \\
\hline Small sapling & 0.674 & & 0.454 & \\
\hline Browse & -0.245 & & 0.060 & \\
\hline Ownership $\rightarrow$ browse & & 0.176 & 0.031 & \\
\hline Subsection $\rightarrow$ small sapling & & 0.275 & 0.076 & \\
\hline \multirow[t]{2}{*}{ Seedling $\rightarrow$ small sapling } & & 0.410 & 0.168 & \\
\hline & & & & 0.789 \\
\hline \multicolumn{5}{|l|}{ Large sapling } \\
\hline Medium sapling & 0.678 & & 0.467 & \\
\hline Small sapling $\rightarrow$ medium sapling & & 0.456 & 0.209 & \\
\hline Browse $\rightarrow$ medium sapling & & 0.166 & 0.028 & \\
\hline Seedling $\rightarrow$ small sapling $\rightarrow$ medium sapling & & 0.278 & 0.077 & \\
\hline \multirow[t]{2}{*}{ Subsection $\rightarrow$ small sapling $\rightarrow$ medium sapling } & & 0.187 & 0.035 & \\
\hline & & & & 0.816 \\
\hline
\end{tabular}

\footnotetext{
$\dagger$ Sum of explained variation for each size class.
} 


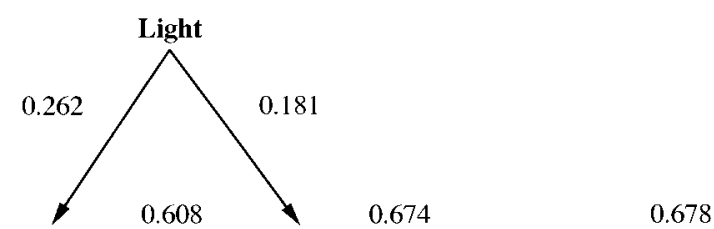

FIG. 6. Path analysis based on inferred causal relationships between variables. Numbers adjacent to arrows indicate the standardized partial regression coefficients (path coefficients) between variables. All direct paths shown are significant at $P<0.05$; direct paths that are not statistically significant have been omitted.

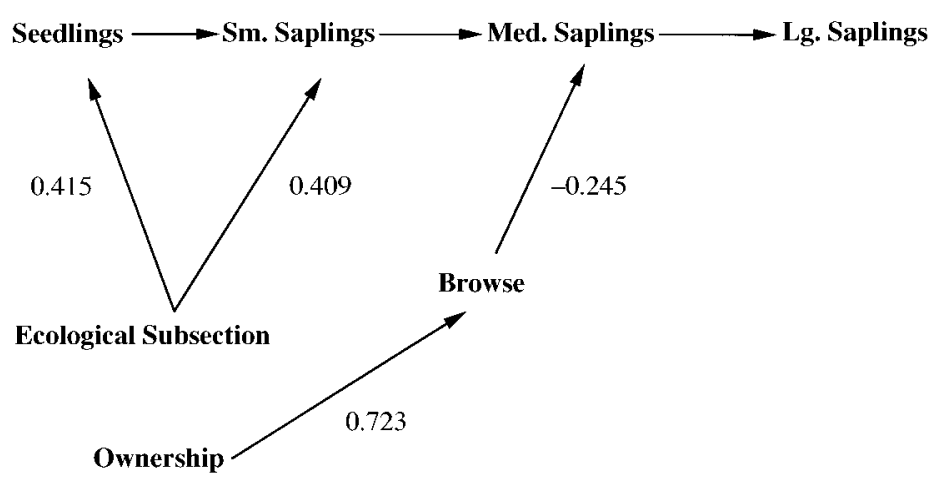

dance where hemlock basal area (and hence needle fall) is highest (Fig. 3). Alternatively, this could support the assertion of Mladenoff and Stearns (1993): hemlock and other conifer seedlings are more abundant at sites where nitrogen availability is low and less abundant where broadleaf litter predominates. High nitrogen availability in decomposed broadleaf litter gives deciduous species a competitive advantage over conifers (Pastor and Mladenoff 1992).

Other factors influencing hemlock abundance operate at larger spatial scales, indicating that hemlock abundance at our study sites is also influenced by the regional context of those sites. Deer browsing pressure and ecological subsection both affect hemlock abundance. Browsing by white-tailed deer only reduces the abundance of medium-sized and large saplings. This probably reflects the fact that large individuals are more conspicuous than smaller individuals (especially during periods of snow cover) and/or that the probability of being browsed increases over time. In either case, herbivory by deer appears to be an important regional factor limiting the abundance of hemlock saplings. Such effects appear to be cumulative and persistent, in that most of the variation in large sapling abundance stems from variation in the abundance of medium-sized saplings. These results are consistent with a regional study of hemlock sapling growth inside and outside deer exclosures, which showed that browsing pressure accounts for most of the increasing size difference between protected and unprotected saplings (Alverson and Waller 1997).

The abundance of hemlock seedlings and small saplings also differed among ecological subsections, with hemlock being less abundant in the BPRM and the LSCP subsections, and more abundant in the GBM subsection. Medium and large saplings were sparse in all subsections except the GBM and NHPO subsections. Deer browsing was lower in these two subsections as many study sites here occurred on Indian reservations with lower deer densities than the surrounding landscape (Alverson et al. 1988, Waller et al. 1996). Although seedling densities in the NHPO subsection paralleled those in other subsections, large saplings were more abundant here, again suggesting that deer were exerting systematic effects. Researchers have only recently examined how coarse-scale heterogeneity affects species distribution and abundance. Regional variation in the abundance of hemlock seedlings and small saplings could not be attributed to the units defined by the Kotar ecological classification system developed for northern Wisconsin (Rooney and Waller 1998). This suggests that the Keys et al. (1995) classification system may better correspond to environmental differences that matter to hemlock. Rykken et al. (1997) examined the distribution of ground beetles and found no relationship between particular species and landtype associations in Vermont, suggesting that these beetles may be responding to either finer or coarser scales of habitat variation.

\section{IMPLICATIONS FOR RESTORATION}

Restoring lost and reduced landscape elements such as eastern hemlock is a regional conservation goal on public lands in Wisconsin (Crow et al. 1994). This restoration has been hampered by uncertainty regarding which factors most affect hemlock establishment and recruitment. In such cases, the most logical way to proceed is to relate data on a wide range of relevant environmental factors across a broad geographic area to seedling and sapling demography that reflects several years' growth (Clark et al. 1999). Here, we analyzed the abundance of several successive demographic size classes both individually and together in order to explore how the separate factors affecting each stage combine to affect overall recruitment. We used path analysis to identify key variables and to probe the na- 
ture, timing, and interaction of their effects. We recommend similar multivariate approaches in other demographic studies when multiple factors affect abundance in order to control for intercorrelated variables and to partition the total variance and so assess the relative importance of individual factors. Such approaches allow researchers to identify key regional variables despite multiple interacting effects possibly acting on more local scales.

Two variables explain most of the regional variation in the recruitment of larger hemlock saplings: the number of smaller saplings at a site and deer browsing intensity. However, much of the regional variation in hemlock seedling abundance remains unexplained. Additional studies should ask how soil moisture and soil texture affect seedling establishment on the forest floor. Also, it is possible that the amount of coarse woody debris within stands may limit seedling establishment (Curtis 1959, Goder 1961). Rooney and Waller (1998) identified rotting wood as an important substrate for seedling establishment at most of our study sites, with seedling densities three times higher on rotting wood than on raised mounds or the forest floor. Further work on the role of coarse woody debris and its role in hemlock's regeneration niche is warranted.

Some researchers have suggested that hemlock could recover if deer population densities were sufficiently reduced (Curtis 1959, Anderson and Loucks 1979, Frelich and Lorimer 1985, Alverson et al. 1988). Seedling establishment is relatively low throughout the BPRM and the LSCP subsections. Thus, hemlock recovery in these subsections may be limited by seedling establishment. Seedling density does not significantly differ in any of the remaining subsections, suggesting that if deer densities were reduced to $4-6$ deer $/ \mathrm{km}^{2}$, hemlock could recover in these other subsections (Alverson et al. 1988).

To retain and restore hemlock within stands over the short term, managers should consider initial seedling and sapling abundance. If large hemlock saplings are abundant, active management will not be necessary in the short term as some saplings are likely to eventually reach the canopy, creating an all-aged stand similar to those found in old growth forests of this type (Frelich and Lorimer 1991, Tyrrell and Crow 1994). In stands lacking large saplings, the potential for hemlock restoration should be assessed by surveying the density of seedlings and small saplings. Where these are abundant, there is potential for recruitment provided browsing is controlled (e.g., by deer-proof fencing or strategic changes in wildlife management goals). Where seedlings and small saplings are scarce, restoration should focus first on enhancing initial establishment. Because seedling establishment is not strongly related to hemlock basal area, merely increasing the proportion of hemlock basal area in stands will not be sufficient to increase hemlock seedling abundance. As indicated, further research is needed to illuminate which com- bination of factors best promotes seedling establishment. It should also be clear, however, that proximal management strategies designed to enhance seedling establishment may do little to ensure hemlock restoration at the stand level where high densities of whitetailed deer are sustained (Alverson et al. 1988, Waller and Alverson 1997).

The long-term prospects for restoration are less certain, particularly in light of climate change. When hemlock became established in the upper Great Lakes 3000 years ago, the climate was warmer and drier than it is at present (Davis et al. 1996). If soil moisture increases with increasing temperatures in northern Wisconsin and Michigan (as predicted by the GISS [Goddard Institute for Space Studies] global circulation model), hemlock may persist. Also, the cool microclimate created by hemlock stands could act as a buffer to reduce soil evaporation. However, if soil moisture decreases (as predicted by the GFDL [Geophysical Fluid Dynamics Laboratory] global circulation model), hemlock will likely be lost from nearly all of the landscape and be replaced by central hardwood species (Davis and $\mathrm{Za}-$ binski 1992). The combination of regional declines in seed production, decreased radial growth, and increased canopy tree mortality over time could signal that the region is becoming less habitable for hemlock. Until there is evidence that hemlock cannot persist in the upper Great Lakes, we advocate hemlock retention and restoration as a technically feasible and politically desirable management objective.

\section{ACKNOWLEDGMENTS}

We thank D. Reiter and P. Huff of the Menominee Nation, and L. Warwoniwitz of the Lac du Flambeau Band of Chippewa, for facilitating access to study sites. K. Borgmann assisted with data entry. W. Alverson, P. Marks, and L. Huenneke shared insightful comments on an earlier draft of this paper. The U. W. Trout Lake Station provided housing. Financial support came from USDA Grant no. 93-00648. This paper is dedicated to the memory of Walter Kuhlmann (19511998): conservationist, scholar, counselor, and friend.

\section{Literature Cited}

Abrams, M. D., and C. M. Ruffner. 1995. Physiographic analysis of witness-tree distribution (1765-1798) and present forest cover through north-central Pennsylvania. Canadian Journal of Forest Research 25:659-668.

Alverson, W. S., W. Kuhlmann, and D. M. Waller. 1994. Wild forests: conservation biology and public policy. Island Press, Washington, D.C., USA.

Alverson, W. S., and D. M. Waller. 1997. Deer populations and the widespread failure of hemlock regeneration in northern forests. Pages 280-297 in W. J. McShea, H. B. Underwood, and J. H. Rappole, editors. The science of overabundance: deer ecology and population management. Smithsonian Institution Press, Washington, D.C., USA.

Alverson, W. S., D. M. Waller, and S. L. Solheim. 1988. Forests too deer: edge effects in northern Wisconsin. Conservation Biology 2:348-358.

Anderson, R. C., and O. L. Loucks. 1979. White-tailed deer (Odocoileus virginianus) influence on the structure and composition of Tsuga canadensis forests. Journal of Applied Ecology 16:855-861. 
Bailey, R. G. 1996. Ecosystem geography. Springer-Verlag, New York, New York, USA.

Braun, E. L. 1950. Deciduous forests of eastern North America. The Blakiston Company, Philadelphia, Pennsylvania, USA.

Caswell, H. 1989. Matrix population models. Sinauer Associates, Sunderland, Massachusetts, USA.

Clark, J. S., B. Beckage, P. Camill, B. Cleveland, J. Hillerislambers, J. Lichter, J. McLachlan, J. Mohan, and P. Wyckoff. 1999. Interpreting recruitment limitation in forests. American Journal of Botany 86:1-16.

Coffman, M. S. 1978. Eastern hemlock germination influenced by light, germination media, and moisture content. Michigan Botanist 17:99-103.

Crow, T. R., A. Haney, and D. M. Waller. 1994. Report on the scientific roundtable on biological diversity convened by the Chequamegon and Nicolet National Forests. U.S. Forest Service General Technical Report NC-166.

Curtis, J. T. 1959. The vegetation of Wisconsin. University of Wisconsin Press, Madison, Wisconsin, USA.

Davis, M. B. 1987. Invasions of forest communities during the Holocene: beech and hemlock in the Great Lakes Region. Pages 373-393 in A. J. Gray, M. J. Crawley, and P. J. Edwards, editors. Colonization, succession, and stability. Blackwell Scientific, Oxford, UK.

Davis, M. B., T. E. Parshall, and J. B. Farrari. 1996. Landscape heterogeneity of hemlock-hardwood forest in northern Michigan. Pages 291-304 in M. B. Davis, editor. Eastern old-growth forests: prospects for rediscovery and recovery. Island Press, Washington, D.C., USA.

Davis, M. B., and C. Zabinski. 1992. Changes in geographical range resulting from greenhouse warming: effects on biodiversity in forests. Pages 297-308 in R. L. Peters and T. E. Lovejoy, editors. Global warming and biological diversity. Yale University Press, New Haven, Connecticut, USA.

Finley, R. W. 1976. Original vegetation cover of Wisconsin. Map compiled from U.S. General Land Office Notes. University of Wisconsin-Extension, Madison, Wisconsin, USA.

Fowells, H. A. 1965. Silvics of the forest trees of the eastern United States. U. S. Forest Service Agricultural Handbook No. 271.

Frelich, L. E., R. R. Calcote, M. B. Davis, and J. Pastor. 1993. Patch formation and maintenance in an old-growth hemlock-hardwood forest. Ecology 74:513-527.

Frelich, L. E., and L. J. Graumlich. 1994. Age-class distribution and spatial patterns in an old-growth hemlock-hardwood forest. Canadian Journal of Forest Research 24: 1939-1947.

Frelich, L. E., and C. G. Lorimer. 1985. Current and predicted long-term effects of deer browsing in hemlock forests of Michigan, USA. Biological Conservation 34:99-120.

Frelich, L. E., and C. G. Lorimer. 1991. A simulation of landscape-level stand dynamics in the northern hardwood region. Journal of Ecology 79:223-233.

Frelich, L. E., and P. B. Reich. 1995. Neighborhood effects, disturbance, and succession in forests of the western Great Lakes region. Ecoscience 2:148-158.

Goder, H. A. 1961. Hemlock reproduction and survival on its border in Wisconsin. Wisconsin Academy of Sciences, Arts and Letters 50:175-181.

Goff, F. G., and D. West. 1975. Canopy-understory interaction effects on forest population structure. Forest Science 21:98-108.

Graham, S. A. 1941. The question of hemlock establishment. Journal of Forestry 39:567-569.

Harper, J. L. 1977. Population biology of plants. Academic Press, London, UK.
Hecnar, S. J., and R. T. M'Closkey. 1996. Regional dynamics and the status of amphibians. Ecology 77:2091-2097.

Hett, J. M., and O. L. Loucks. 1976. Age structure models of balsam fir and hemlock. Journal of Ecology 64:10291044.

Hough, A. F. 1960. Silvicultural characteristics of eastern hemlock. U.S. Forest Service Northeastern Experiment Station Paper 132.

Hough, A. F. 1965. A twenty-year record of understory vegetational change in a virgin Pennsylvania forest. Ecology 46:370-373.

Hough, A. F., and R. D. Forbes. 1943. The ecology and silvics of forests in the high plateaus of Pennsylvania. Ecological Monographs 13:299-320.

James, F. C., C. A. Hess, and D. Kufrin. 1997. Speciescentered environmental analysis: indirect effects of fire history on red-cockaded woodpeckers. Ecological Applications 7:118-129.

Keys, J., Jr., C. Carpenter, S. Hooks, F. Koening, W. H. McNab, W. Russell, and M. L. Smith. 1995. Ecological units of the eastern United States-first approximation. U.S. Forest Service, Atlanta, Georgia, USA.

Kobe, R. K. 1996. Intraspecific variation in sapling mortality and growth predicts geographic variation in forest composition. Ecological Monographs 66:181-201.

Kohm, K. A., and J. F. Franklin, editors. 1997. Creating a forestry for the 21 st century: the science of ecosystem management. Island Press, Washington D.C., USA.

Kotar, J. 1996. Relative importance and regeneration success of hemlock on different habitat types. Pages 91-97 in G. Mroz and J. Martin, editors. Hemlock ecology and management: proceedings of a regional conference on ecology and management of eastern hemlock. Department of Forestry, Michigan Technical University, Houghton, Michigan, USA.

Kotar, J., A. Kovach, and C. T. Loecy. 1988. Field guide to forest habitat types of northern Wisconsin. Department of Forestry, University of Wisconsin, Madison, Wisconsin, USA.

Li, C. C. 1975. Path analysis. Boxwood Press, Pacific Grove, California, USA.

Maissurow, D. K. 1941. The role of fire in the perpetuation of virgin forests of northern Wisconsin. Journal of Forestry 39:201-207.

Matson, P. A., and R. H. Waring. 1984. Effects of nutrient and light limitation on mountain hemlock: susceptibility to laminated root rot. Ecology 65:1517-1524.

McShea, W. J., and J. H. Rappole. 1992. White-tailed deer as keystone species within forested habitats of Virginia. Virginia Journal of Science 43:177-186.

Mladenoff, D. J., and F. Stearns. 1993. Eastern hemlock regeneration and deer browsing in the Great Lakes Region: a re-examination and model simulation. Conservation $\mathrm{Bi}$ ology 7:889-900.

Mladenoff, D. J., M. A. White, T. R. Crow, and J. Pastor. 1994. Applying principles of landscape design and management to integrate old-growth forest enhancement and commodity use. Conservation Biology 8:752-762.

Mladenoff, D. J., M. A. White, J. Pastor, and T. R. Crow. 1993. Comparing spatial pattern in unaltered old-growth and disturbed forest landscapes. Ecological Applications 3: 294-306.

Nichols, G. E. 1935. The hemlock-white pine-northern hardwood region of eastern North America. Ecology 16:403422.

Noss, R. F., and A. Y. Cooperrider. 1994. Saving nature's legacy: protecting and restoring biodiversity. Island Press, Washington, D.C., USA.

Ostfeld, R. S., and C. D. Canham. 1993. Effects of meadow 
vole population density on tree seedling survival in old fields. Ecology 74:1792-1801.

Pastor, J., and M. Broschart. 1990. The spatial pattern of a northern conifer-hardwood landscape. Landscape Ecology 4:55-68.

Pastor, J., and D. J. Mladenoff. 1992. The southern borealnorthern hardwood forest border. Pages 216-240 in $\mathrm{H}$. $\mathrm{H}$. Shugart, R. Leemans, and G. B. Bonan, editors. A systems analysis of the global boreal forest. Cambridge University Press, Cambridge, UK.

Perry, D. A. 1994. Forest ecosystems. Johns Hopkins University Press, Baltimore, Maryland, USA.

Pubanz, D. M. 1996. Regeneration and historical growth patterns in large-diameter hemlock on Menominee Tribal Lands. Pages 175-177 in G. Mroz and J. Martin, editors. Hemlock ecology and management: proceedings of a regional conference on ecology and management of eastern hemlock. Department of Forestry, Michigan Technical University, Houghton, Michigan, USA.

Robinson, S. K., F. R. Thompson, T. M. Donovan, D. R. Whitehead, and J. Faaborg. 1995. Regional forest fragmentation and the nesting success of migratory birds. Science 267:1987-1990..

Rogers, R. S. 1978. Forests dominated by hemlock (Tsuga canadensis): distribution as related to site and postsettlement history. Canadian Journal of Botany 56:843-854.

Rooney, T. P. 1995. Restoring diversity and old growth to Pennsylvania's northern hardwood forests. Natural Areas Journal 15:274-278.

Rooney, T. P., and W. J. Dress. 1997. Patterns of plant diversity in overbrowsed primary and mature secondary hemlock-northern hardwood forest stands. Journal of the Torrey Botanical Society 124:43-51.

Rooney, T. P., and D. M. Waller. 1998. Local and regional variation in hemlock seedling establishment in the forests of the upper Great Lakes region, USA. Forest Ecology and Management 111:211-224.

Rykken, J. J., D. E. Capen, and S. P. Mahabir. 1997. Ground beetles as indicators of land type diversity in the Green Mountains of Vermont. Conservation Biology 11:522-530.

Sokal, R. R., and F. J. Rohlf. 1981. Biometry. Second edition. W.H. Freeman, New York, New York, USA.

Stearns, F. 1947. The composition of the sugar maple-hemlock-yellow birch association in northern Wisconsin. Dis- sertation. University of Wisconsin, Madison, Wisconsin, USA.

Tyrrell, L. E., and T. R. Crow. 1994. Structural characteristics of old-growth hemlock-hardwood forests in relation to age. Ecology 75:370-386.

Underwood, A. J., and P. S. Petraitis. 1993. Structure of intertidal assemblages in different locations: how can local processes be compared? Pages 39-51 in R. E. Ricklefs and D. Schluter, editors. Species diversity in ecological communities: historical and geographical perspectives. The University of Chicago Press, Chicago, Illinois, USA.

Vander Zouwen, W., and K. Warnke. 1995. Deer population goals and harvest management environmental assessment. Wisconsin Department of Natural Resources, Madison, Wisconsin, USA.

Waller, D. M., and W. S. Alverson. 1997. The white-tailed deer: a keystone herbivore. Wildlife Society Bulletin 25: 217-226.

Waller, D. M., W. S. Alverson, and S. L. Solheim. 1996. Local and regional factors influencing the regeneration of eastern hemlock. Pages 73-90 in G. Mroz and J. Martin, editors. Hemlock ecology and management: proceedings of a regional conference on ecology and management of eastern hemlock. Department of Forestry, Michigan Technical University, Houghton, Michigan, USA.

White, M. A., and D. J. Mladenoff. 1994. Old-growth forest landscape transitions from pre-European settlement to present. Landscape Ecology 9:191-205.

Whitney, G. G. 1994. From coastal wilderness to fruited plain: a history of environmental change in temperate North America from 1500 to the present. Cambridge University Press, Cambridge, UK.

Wiens, J. A. 1997. Metapopulation dynamics and landscape ecology. Pages 43-62 in I. A. Hanski and M. E. Gilpin, editors. Metapopulation biology: ecology, genetics, and evolution. Academic Press, San Diego, California, USA.

Wilcove, D. S. 1985. Nest predation in forest tracts and the decline of migratory songbirds. Ecology 66:1211-1214.

Wilkinson, L., G. Blank, and C. Gruber. 1996. Desktop data analysis with SYSTAT. Prentice-Hall, Upper Saddle River, New Jersey, USA.

Willis, G. L., and M. S. Coffman. 1975. Composition, structure, and dynamics of climax stands of eastern hemlock and sugar maple in the Huron Mountains, Michigan. Technical Bulletin No. 13, Department of Forestry, Michigan Technological University, Houghton, Michigan, USA. 